\title{
FLAT DESIGN APLICADO AO DESIGN DE INTERFACES: UMA ANÁLISE ACERCA DA ESTÉTICA VISUAL E DA USABILIDADE DA TENDÊNCIA FLAT
}

\author{
Jéssica Rodrigues Esteves \\ Universidade Federal de Pelotas \\ jess.re@gmail.com \\ Tobias Mülling \\ Universidade Federal de Pelotas \\ tmulling@gmail.com
}

Resumo: Este artigo apresenta o resultado de uma análise sobre o Flat Design, uma tendência estética contemporânea utilizada no design de interfaces. Com base na observação recorrente do uso da estética, bem como na sua popularização entre designers e usuários, a pesquisa se propõe a identificar o Flat Design enquanto tendência, abordando os fatores tecnológicos que contribuíram para sua difusão do mercado; propondo uma breve abordagem sobre o web design responsivo, mostrando de que maneira o flat pode contribuir na implementação desta prática; analisando projetos de interface que contemplem o uso do Flat Design, sistematizando as características visuais do flat enquanto tendência; discutindo acerca da usabilidade e interação, identificando eventuais falhas no processo de entendimento dos elementos da interface. Com base nas análises, foi possível apontar algumas vantagens e desvantagens do Flat Design enquanto tendência estética. Assim, a pesquisa propõem a refletir acerca da tendência flat, discutindo sobre estética e usabilidade com o objetivo de contribuir para o aperfeiçoamento do campo de estudo sobre estética no design de interfaces.

Palavras-chave: Interface, Web Design, Estética, Flat Design

Abstract: This article presents the results of an analysis on the Flat Design, a contemporary aesthetic trend used in the design of interfaces. Based on the recurrent observation of the use of aesthetics as well as its popularity among designers and users, the research aims to identify the Flat Design trend while addressing technological factors that contributed to its spread in the market; propose a brief approach to responsive web design, showing how the flat can contribute in the implementation of this practice; analyze interface projects that include the use of Flat Design, systematizing the visual characteristics of the flat as a trend; argue about the usability and interaction, identifying any gaps in the understanding of the elements of the interface process. Based on the analysis, it was possible to point out some advantages and disadvantages of the flat design as an aesthetic trend. Thus, the research proposes to reflect on the flat trend, discussing 
aesthetics and usability in order to contribute to the improvement of the field of study of aesthetics in the design of interfaces.

Keywords: Interface, Web Design, Aesthetics, Flat Desig.

\section{INTRODUÇÃO}

Na atualidade, observa-se que o Flat Design tornou-se uma tendência estética por ser utilizada na interface de grandes empresas como a Google, a Apple e a Microsoft. Desta forma, ela foi difundindo-se entre designers e usuários. Em um primeiro momento, houve um choque devido a sua estética com poucos elementos visuais, diferentemente do que vinha sido utilizado até o momento. Após um período de aceitação, alavancado pelo uso frequente do flat, a tendência adquiriu popularidade e relevância no design de interfaces.

Além das questões culturais que levaram a difusão do Flat Design, observam-se influências tecnológicas, como a utilização do web design responsivo. Este pode ser entendido como uma abordagem de web design destinada a desenvolver sites para fornecer uma ótima experiência de visualização, fácil leitura e navegação, com um mínimo de redimensionamento e visionamento, para uma ampla gama de dispositivos, de monitores de computadores a smartphones. O web design responsivo é potencializado a partir do uso do flat, devido a utilização de elementos sólidos e poucas imagens, a interface pode ser implementada em grande parte somente com a codificação da mesma - com baixo uso de imagens. Isso faz com que seja mais fácil realizar adaptações para diferentes resoluções, fazendo com que este seja muito promissor no web design responsivo.

Com base na utilização recorrente do Flat Design, é importante que designers compreendam os pontos positivos e negativos associados a tendência, a fim de perceber se ela é realmente a melhor solução para um projeto. Portanto, o objetivo desta pesquisa é apresentar características visuais do flat, a partir de uma compilação de interfaces que utilizam a tendência. Essas interfaces foram escolhidas devido a sua qualidade estética, de modo que fosse possível analisar os elementos que compõe os fundamentos do design definidos por Lupton e Phillips (2008), sendo eles: simetria e estabilidade, escala, cor, figura e fundo, modularidade e grid. Outro ponto abordado foi a usabilidade, com base em testes e análises realizadas por Nielsen (2012) e Budiu (2013). Assim, o objetivo deste artigo é a sistematização das características visuais com o objetivo de compreender conceitos universais de design aplicativos a tendência, servindo como um guia para designers compreenderem a estética flat.

\section{DESENVOLVIMENTO}

O problema de estudo desta pesquisa é identificar as características visuais e projetuais do Flat Design enquanto tendência. Para isso, foi utilizado o método indutivo, a fim de buscar-se uma abordagem qualitativa. Dessa forma, foram analisados dados particulares para buscar uma verdade geral ou universal não contida nas partes examinadas (LAKATOS E MORI, 2010). O método indutivo foi realizado a partir de revisão bibliográfica e análises. 
A revisão bibliográfica tratou de assuntos como identificação do Flat Design enquanto tendência, abordando aspectos históricos que ocasionaram a sua propagação; conceituação do web design responsivo, tendo como referencial as definições de Marcotte (2011); a definição das características visuais a partir dos conceitos de Lupton e Phillips (2008); discussão acerca da usabilidade e interação, utilizando as análises realizadas por Nielsen (2012) e Budiu (2013).

\subsection{Flat Design enquanto tendência}

O uso da palavra tendência é algo comum em nosso cotidiano. A origem etimológica da palavra tendência denota do latim tendentia, particípio presente e nome plural substantivado do verbo tendere, que significa "tender para", "inclinar-se para" ou "atraído por" (CALDAS, 2004). Existem inúmeras definições de especialistas que buscam delinear o significado de palavra. Para este trabalho, vamos nos abster de traçar discussões mais profundas acerca da temática e compreender o significado da palavra a partir de uma constatação universal: uma tendência possui relação com a ideia de mudanças. No campo de estudo do design de interface, pode-se identificar tendências a partir de mudanças em padrões de design por produtos que possuam relevância e notoriedade no mercado.

$\mathrm{Na}$ atualidade, o design de interfaces voltou-se para a ideia funcionalista do "menos é mais", prezando pela usabilidade e menor carga informacional e visual. Considerando os aspectos estéticos de uma interface, pode-se encontrar principalmente duas tendências, o Skeuomorphism e o Flat Design. A tendência estética utilizada nos últimos anos ainda possui relação com a primeira interface gráfica do usuário (GUI) da Xerox PARC de 1973, que utilizava elementos do mundo real para que o usuário possa se familiarizar com a interface do computador. Esta tendência foi denominada Skeuomorphism, sendo caracterizada pela utilização de sombras, gradientes, texturas, relevos, entre outros elementos, para imitar objetos do mundo real em um ambiente digital, a fim de familiarizar o usuário com a interface. No entanto, observa-se a existência de uma nova tendência, sendo utilizada na interface de grandes empresas de tecnologia como o Google, a Apple e a Microsoft. Desta forma, o Flat Design surgiu sendo caracterizado como uma estética visual que preza pela forma, funcionalidade e tecnologia.

A tendência flat pode ser compreendido como uma "filosofia de design que defende uma simplicidade, clareza e honestidade de materiais em interfaces de usuário..." (DOLLAGHAN, 2013). Do ponto de vista prático, o Flat Design utiliza cores sólidas, tipografia sem serifa e iconografia plana (figura e fundo). Já do ponto de vista técnico, a tendência possui a vantagem de ser implementada somente com códigos, já que a interface usa poucas ou nenhuma imagem. Isso faz com que seja mais fácil realizar adaptações para diferentes resoluções, fazendo com que este seja muito promissor no web design responsivo. ${ }^{1}$

A estética flat não é algo genuíno do mundo contemporâneo. Observa-se no decorrer da história do design gráfico, movimentos artísticos com o mesmo propósito,

\footnotetext{
${ }^{1}$ Web design responsivo faz com que os elementos se adaptem automaticamente à largura de tela do dispositivo no qual ele está sendo visualizado.
} 
como o Estilo Internacional ${ }^{2}$ e a Bauhaus ${ }^{3}$. Constata-se assim que os estilos de design são reinventados quando a estética torna-se monótona para o usuário, devido ao uso frequente e excessivo por parte dos designers.

Em interfaces flat, observa-se a redução de elementos visuais, como sombras, gradientes, texturas, ou qualquer outro que possa poluir e causar interferência visual. O Flat Design vai contra a premissa de que para se ter uma interface atraente é necessário adicionar muitas camadas de efeitos. Ao reduzir uma interface ao essencial utilizando formas puras - círculo, retângulo, triângulo -, valorização do conteúdo e aproveitamento máximo de cores e tipografia, ela torna-se atraente e sofisticada. Embora pareça simples, isso não significa que o Flat Design é fácil de ser executado. A estética exige que o designer faça um estudo atencioso de cores, tipografias e elementos visuais.

Atribui-se a popularização da tendência ao lançamento da Metro UI, uma interface gráfica desenvolvida pela Microsoft baseada em princípios do design funcionalista, originalmente desenvolvimento para o uso no sistema operacional dos móvel da empresa (tablets e o smartphone da Microsoft, o Windows Phone) e posteriormente adotada para o sistema operacional para computadores (Windows 8). Essa interface surpreendeu os usuários por possuir uma aparência estética diferente do que vinha sendo utilizado em interfaces digitais. Acredita-se que simplificação das interfaces gráficas foi necessária, tendo em vista o tamanho e a resolução da tela dos dispositivos móveis, como smartphones e tablets. A Metro UI é baseado nos princípios clássicos da escola suíça de design gráfico. De acordo com a Microsoft, o nome dado à linguagem de design representa toda a velocidade, autenticidade e modernidade utilizada, bem como a constante "movimentação" do seu código - o que nos leva a crer que ele esteja em constante desenvolvimento. Para o design visual, a Microsoft utilizou uma aparência estética mais limpa, excluindo elementos gráficos supérfluos ao sistema operacional. A Metro UI foi projetada para tornar a experiência dos usuários mais agradável e fluída; para isso, a interface utiliza botões e títulos grandes, ícones planos (figura e fundo), tipografia sem serifa e com variações de tamanho, além de transições mais suaves para a navegação entre as telas.

Na figura 1, é possível observar as mudanças do Windows 7 em comparação com o Windows 8: no primeiro, a barra de tarefas está organizada em uma barra inferior retangular; os ícones são pequenos, organizados dentro da barra de tarefas, seu tratamento estético preza o realismo, fazendo o uso de sombras e gradientes. Já no Windows 8 , os elementos são grandes e ocupam praticamente toda a tela; os ícones são grandes e com desenho simplificado, organizado dentro de blocos coloridos; a barra de tarefas está localizada em uma barra lateral retangular, do lado direito da tela. Essas características de cor, forma e organização do conteúdo

\footnotetext{
2 O Estilo Internacional surgiu em 1950 na Suíça e Alemanha, tendo clareza e ordem como palavraschave (MEGGS, 2006, p. 463). Sendo uma vertente do funcionalismo, o Estilo Internacional acreditava no princípio de que "a forma segue a função", de modo que qualquer ornamento era considerado inútil. (Ibid., 2006)

${ }^{3}$ A Escola Bauhaus, fundada em 1919 na Alemanha, tinha o objetivo de unir arte e indústria. Os objetos deveriam ser funcionais, concretos, simples e racionais, sem qualquer ornamentação das formas. (MEGGS, 2006).
} 
permitem constatar que o Windows 7 representa o Skeuomorphism e o Windows 8 o Flat Design.

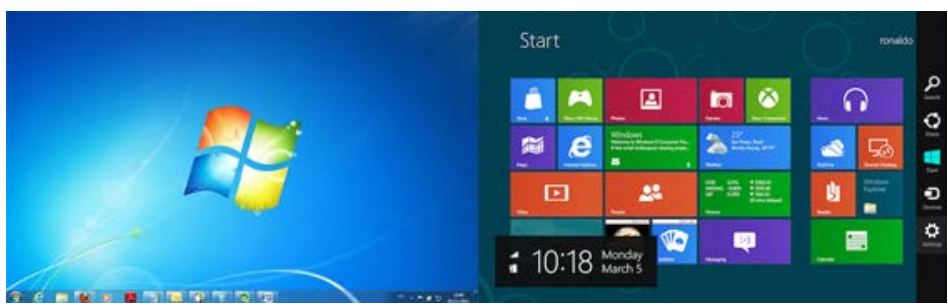

Figura 1 - Desktop Windows 7 e Windows 8, respectivamente. Fonte: (http://zip.net/bvlBNT).

Após a mudança de design da Microsoft, a Apple também realizou mudanças na interface do sistema iOS. Em comparação ao iOS6, o iOS7 é mais simplificado e colorido. Seguindo a mesma transição da Microsoft, identificada na figura 1, a Apple revitalizou o sistema iOS. As versões anteriores possuíam como referencial estético o Skeuomorphism, caracterizado pelo uso de texturas, sombras e efeitos em 3D. No iOS 7, observa-se uma grande mudança, fazendo com que a interface seja mais flat. $\mathrm{Na}$ figura 2, pode-se observar as mudanças nos dois sistemas operacionais. No iOS6, os ícones possuíam efeitos visuais, tais como sombras, chanfros e texturas que the conferiam a ideia de profundidade. Já no iOS 7, observa-se uma grande simplificação do desenho dos ícones, além de uma redução na quantidade de gradientes e sombras em comparação aos ícones do iOS 6 . Os ícones do novo sistema operacional possuem cores mais vibrantes e alegres, contribuindo para que a interface adquira um visual mais jovem e contemporâneo.

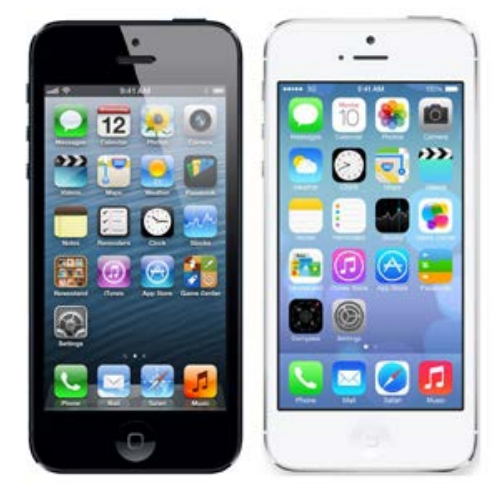

Figura 2 - iOS 6 e 7, respectivamente.

Fonte: (http://zip.net/bllzzD)

\subsection{Web Design Responsivo}

O web design é uma extensão da prática do design, com foco na criação de sites para a Internet. É uma prática relativamente nova, portanto encontra-se em constante evolução. A estrutura de um website é uma parte importante no processo de implementação do mesmo. Os primeiros websites eram criados com estruturas fixas, ou seja, projetados para computadores com resolução específica. Com a popularização dos computadores com diferentes resoluções, passou-se a adotar uma estrutura com layout flexível. Essa estrutura acabava causando transtornos, justamente por ser flexível demais: apenas os textos eram flexibilizados, as imagens não se adaptavam, as 
telas dos navegadores não podiam ser muito esticadas. Este cenário fez com que designers e desenvolvedores buscassem uma técnica que se adaptasse a realidade da web atual, que possui uma grande variedade de dispositivos e resoluções.

A maioria dos softwares e aplicativos é desenvolvida para um determinado sistema operacional, e deve-se levar em consideração as características do dispositivo em que será aplicado: tamanho, densidade, como o nível de brilho do display afeta a visualização das cores, as fontes embarcadas, sua velocidade de processamento e memória e, principalmente, a usabilidade. Portanto, uma interface fluída e adaptável ao tamanho da tela é uma solução. O web design responsivo é uma abordagem de web design destinada a desenvolver sites para fornecer uma ótima experiência de visualização, fácil leitura e navegação, com um mínimo de redimensionamento e visionamento, para uma ampla gama de dispositivos - de monitores de computadores a smartphones - (MARCOTTE, 2011).

Com base no todo exposto, observam-se vantagens na utilização do Flat Design para o web design responsivo. Utilizando GUIs planas, cores sólidas e iconografia simples são vantagens que o Flat Design pode oferecer para facilitar o processo de criação de interfaces para designers e desenvolvedores, pois minimiza a refação para cada sistema operacional, reduzindo o peso dos elementos, e, consequentemente, diminuindo o tempo de espera para carregar a interface na tela do usuário. 0 web design responsivo é potencializado a partir do uso do flat, ou seja, quando ocorrem as trocas de tamanho de tela os backgrounds, botões e outros elementos desenvolvidos de maneira flat podem ter variação de tamanho, tanto horizontal quanto vertical sem necessitar de imagens especiais para tal, onerando o usuário em novos carregamentos de imagens.

\subsection{Características visuais Flat Design}

Para a definição das características visuais do Flat Design, foi realizada uma análise a partir dos conceitos de Lupton e Phillips (2008), abordando os novos fundamentos do design, buscando compreender conceitos universais de design aplicados a tendência estética.

\subsubsection{Simetria e estabilidade}

A simetria é a semelhança exata da forma em torno de uma determinada linha reta (eixo), ponto ou plano. É uma das formas de se alcançar o equilíbrio visual de uma imagem. Ele acontece quando "o peso de uma ou mais coisas está distribuído igualmente ou proporcionalmente no espaço, podendo ser identificado pela simetria ou assimetria" (Ibid.,p. 29). A estabilidade possui relação com o equilíbrio e o ritmo, definindo a ideia de movimento na imagem. No design de interfaces, a simetria e a estabilidade podem denotar segurança e confiabilidade, tendo em vista que a interface possui uma padrão visual que pode ser identificado claramente pelo usuário. Desta forma, o Flat Design utiliza esses dois fundamentos a favor da usabilidade. No entanto, designers podem utilizar a assimetria para dar ritmo e dinamismo à interface.

A figura 3 mostra duas formas de utilização da simetria e assimetria no Flat Design. Na primeira imagem da figura 3, os elementos estão organizados de forma proporcional, ocupando as extremidades da interface. Já na segunda imagem, a 
interface é composta por módulos de diferentes tamanhos. Isto lhe confere uma sensação de movimento e ritmo.

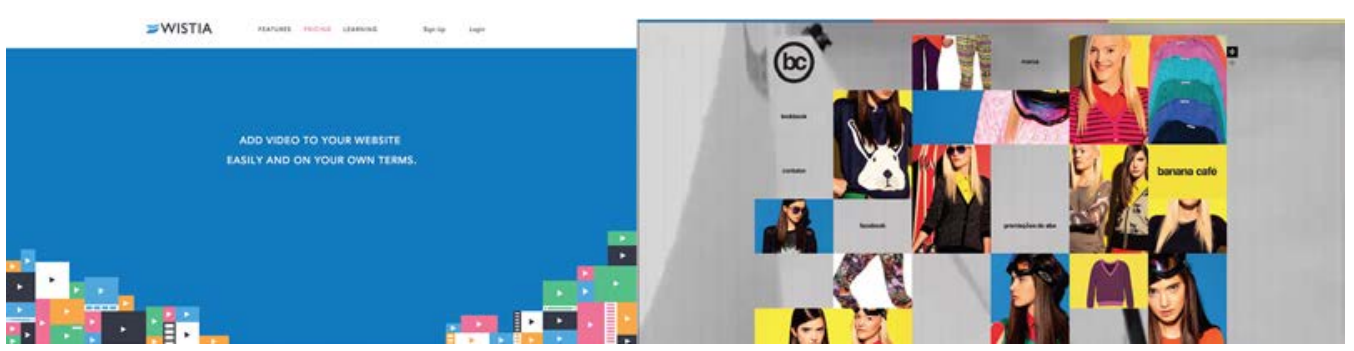

Figura 3 - Simetria: elementos organizados de forma proporcional.

Fonte: (wistia.com)

\subsubsection{Escala}

A escala se refere às dimensões de um elemento em uma imagem, podendo acontecer de forma objetiva ou subjetiva. De forma objetiva, "ela se refere às dimensões exatas de um objeto físico ou à correlação exata entre uma representação e a coisa real que ela representa" (Ibid.,p. 42). Subjetivamente, a escala dá a impressão que alguém tem o tamanho de um objeto.

Em interfaces flat, observa-se a utilização de elementos em grande escala, como podemos observar na figura 4. Para os dispositivos móveis, elementos grandes favorecem a usabilidade da interface, tendo em vista as dimensões de tela. Nas interfaces para web, elementos em grande escala enfatizam a usabilidade e clareza de informações. Além disso, como uma interface flat possui a adaptabilidade em diversos dispositivos, devem-se observar as dimensões dos elementos da tela para que não comprometa a legibilidade.

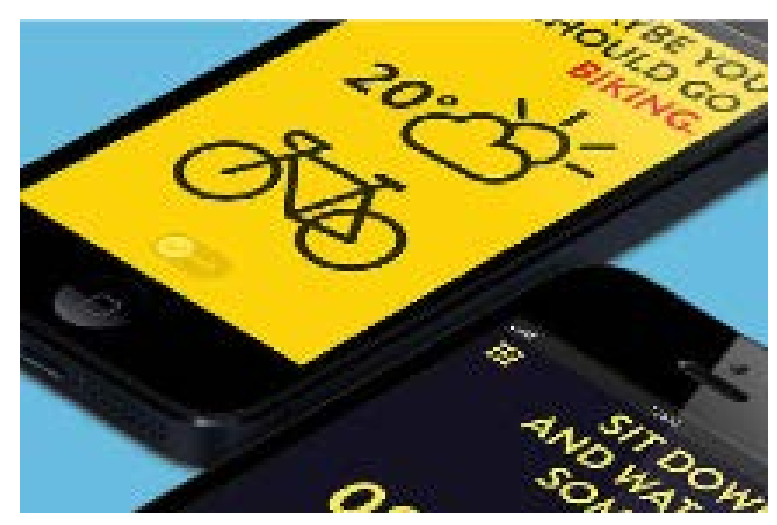

Figura 4 - Escala em dispositivos móveis.

Fonte: Pinterest.com

\subsubsection{Cor}

As cores são capazes de "exprimir uma atmosfera, descrever uma realidade ou codificar uma informação” (Ibid.,p. 29). São capazes de transmitir sensações, emoções e sentimentos; possuindo um sentido diferente de uma cultura para outra. Para $o$ Flat Design, a cor é um dos elementos essencial. Devido à utilização de poucos recursos visuais, a cor, juntamente com a tipografia, o grid e a iconografia são elementos que 
caracterizam a tendência. Não existe uma paleta de cores específicas para o Flat Design, pois observa-se a utilização de uma grande variedade de cores. No entanto, é possível identificar o uso de cores saturadas em contraste com cores neutras. As paletas possuem de 2 a 4 cores, sendo grandes matizes brilhantes, saturadas em contraste com cinzas ou pretos. Tom e saturação são combinados, criando cores brilhantes e vibrantes. Cores vibrantes possuem boa legibilidade contra a luz e em fundos escuros, criando contraste e proporcionando uma energia visual, fazendo com que usuários sejam atraídos por ela. Combinações com azuis, verdes e roxos são as mais populares no Flat Design. Um exemplo de paleta de cores vibrantes é a proposta pelo site Flat UI Colors (http://flatuicolors.com/), identificada na figura 5. Este disponibiliza uma coleção de cores flat, com base nas cores mais utilizadas por designers em interfaces que seguem a tendência.

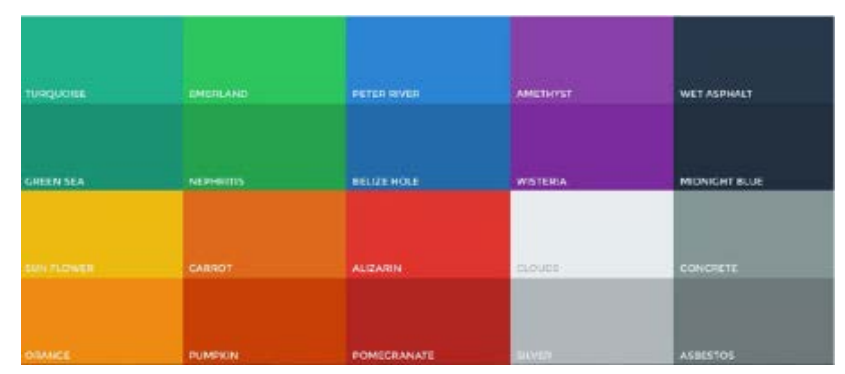

Figura 5 - Paleta Flat UI Colors.

Fonte: Flatuicolors.com

\subsubsection{Figura e fundo}

O conceito aborda que a forma de um objeto não é mais importante que a forma do espaço em torno dele (GREAR apud LUPTON e PHILLIPS, 2008). As relações entre figura e fundo definem a percepção visual, de modo que uma forma sempre é observada em relação ao fundo. No Flat Design, percebe-se a utilização da relação figura e fundo nos ícones, como mostra a figura 6 . Em grande parte dos produtos, os ícones utilizados possuem apenas uma cor e são utilizados sob um fundo modular colorido. O fundo auxilia o usuário a distinguir o ícone dos outros.

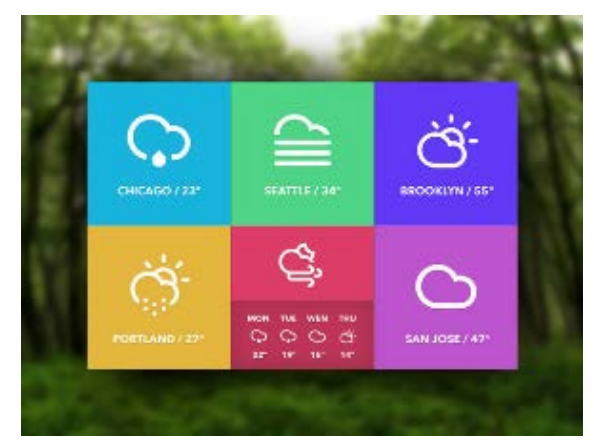

Figura 4 - Figura e fundo.

Fonte: Pinterest.com 


\subsubsection{Modularidade e grid}

De acordo com Lupton e Phillips, um módulo é "um elemento fixo utilizado no interior de um sistema ou estrutura maior" (Ibid., p. 159). Um pixel, por exemplo, é um módulo que constrói uma imagem digital. O grid é uma rede de linhas (Ibid.,p. 179) que facilitam a organização das informações em um projeto de design, tanto em livros quanto em interfaces. Ele auxilia os designers a alinharem os elementos, utilizando linhas-guias, margens e colunas.

Módulos são caixas de informação que podem ser dispostos de maneira simétrica ou assimétrica. Eles demarcam o espaço a ser ocupado por imagens, vídeos, etc. No Flat Design, observa-se a utilização de uma grid modular. O grid modular auxilia no redimensionamento e adaptação do layout para outros dispositivos, utilizando-se a técnica de web design responsivo, conforme foi abordado anteriormente. A figura 7 mostra a tela inicial do Windows 8. Observa-se que o layout é construído a partir de módulos e, por serem em sua maioria flat, torna-se possível a escalabilidade no tamanho. Os ícones e tipografias em branco, aplicados sob módulos coloridos possuem uma boa relação de contraste entre figura e fundo. Além disso, os módulos possuem relação com o web design responsivo, visto que facilitam o redimensionamento dos blocos para telas menores ou maiores.

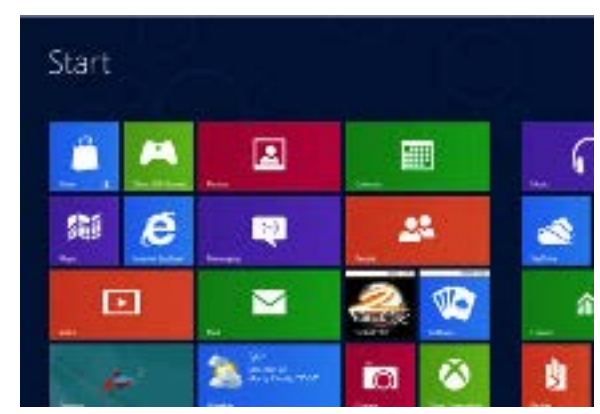

Figura 7 - Interface Windows 8.

Fonte: (zip.net/bdmpGp)

\subsection{Usabilidade}

O Flat Design preza pela funcionalidade, a partir da hierarquia na concepção e organização dos elementos, com o objetivo de facilitar a compreensão e interação dos usuários. No entanto, a falta de affordances ${ }^{4}$ e a ausência de profundidade dos elementos podem ocasionar uma falha na compreensão do usuário sobre o que é clicável. Esses são alguns dos problemas de interação apresentado por interfaces flat.

Nielsen (2012) discutiu a usabilidade do Windows 8 , mostrando um novo ponto de vista acerca da interação do usuário com a interface. $O$ autor realizou um teste de usabilidade com 12 usuários experientes, onde foi possível identificar problemas na usabilidade do Windows 8 . Os usuários utilizaram o novo sistema operacional da

\footnotetext{
4 Affordances referem-se "às propriedades percebidas e reais de um objeto, principalmente as propriedades fundamentais que determinam de que maneira o objeto poderia ser usado" (NORMAN, 2006, p. 33). No design de interfaces, as affordances podem ser representadas por elementos de interação, como: ícones, botões, links, janelas e menus. Esses elementos "falam por sí", ou seja, sugerem uma ideia de ação
} 
Microsoft em computadores regulares, bem como em novos computadores e tablets da empresa. Entre suas principais críticas estão a sobrecarga de memória para tarefas complexas, a redução da descoberta e a baixa densidade informacional.

De acordo com o autor, um dos piores aspectos do Windows 8 para usuários experientes é a falta de várias janelas na tela, ocasionando a sobrecarga de memória para tarefas simples. O novo sistema operacional possui uma segunda área, em uma pequena parte da tela, mas nenhum dos usuários do teste conseguiu encontrá-la. A estratégia de janela única possui uma boa funcionalidade em tablets e smartphones. No entanto, em desktops com monitores grandes que possuem vários aplicativos e sites sendo utilizados ao mesmo tempo, a janela única não permite que o usuário possa visualizar vários sites ao mesmo tempo.

A redução da descoberta possui relação com as características visuais do Flat Design, caracterizada por uma interface plana. De acordo com o autor, os efeitos 3D e utilização de sombras sutis, auxiliavam o processo de compreensão dos elementos de interface, mostrando para o usuário o que era clicável. Nielsen (2012) mostra-se favorável ao estilo flat no que diz respeito a estética, exaltando a utilização de tipografia e uso de cores contrastantes. No entanto, o autor acredita que a falta de elementos visuais pode ocasionar grandes problemas na descoberta e entendimento dos elementos de interface.

A figura 8, mostra a parte inferior do menu de configurações do Windows 8. 0 fundo é composto por uma cor sólida e os ícones são planos, adquirindo grande contraste devido ao fundo escuro. Abaixo de cada ícone, encontra-se o nome da sua funcionalidade. No lado esquerdo da figura, abaixo dos ícones, encontre-se o comando "Change PC settings" 5 , sendo definido apenas pelo uso da tipografia. Nos testes de usabilidade elaborados por Nielsen (2012), muitos usuários não clicavam neste comando para acessar seus recursos. Esses usuários não conseguiam identificar que o rótulo "Change PC settings" é na verdade um comando que esconde outras funcionalidades. A utilização de ícones planos, monocromáticos e extremamente simplificados pode fazer com que os usuários não percebam quais elementos devem "clicados" ou "tocados" para que se possa interagir com a interface.

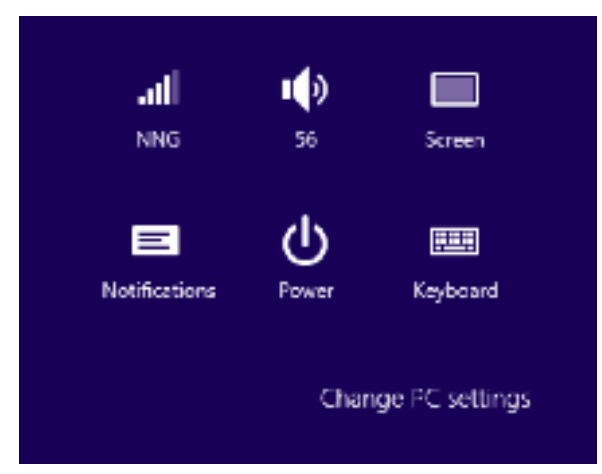

Figura 8 - Menu de configurações do Windows 8.

Fonte: (http://zip.net/bpmp1X)

A baixa densidade informacional diz respeito à utilização de pouco conteúdo na interface. De acordo com Nielsen (2012), parece existir uma premissa entre designers

\footnotetext{
${ }^{5}$ Traduzido para português: "Mudar as configurações do computador" (tradução livre).
} 
que para projetar um estilo moderno de interface, deve-se criar aplicativos com uma baixa densidade de informações. A figura 9 mostra o aplicativo Big Finance, exibido em um tablet de 10,6 polegadas. Observa-se que o aplicativo mostra apenas uma notícia e abaixo dela três citações do mercado de ações, na sua tela inicial.

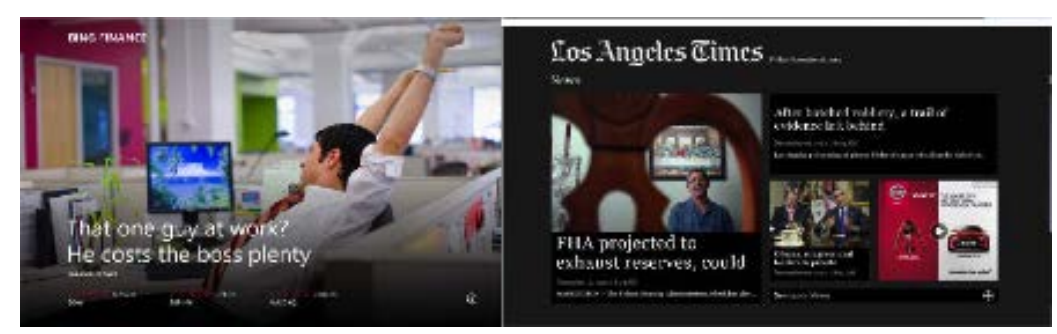

Figura 9 - Aplicativo Big Finance e LA Times, respectivamente.

Fonte: (http://zip.net/bpmp1X)

O aplicativo Los Angeles Times, também na figura 13, não apresenta um bom aproveitamento de espaço. A tela inicial é limitada a três títulos e um anúncio. A manchete completa da notícia principal não é mostrada e o resumo possui espaço para apenas 7 palavras. Desta forma, observa-se que em uma tela de 1366x768, o espaço poderia ser melhor aproveitado, incluindo mais informações nos ambos aplicativos. Isso diminuiria a rolagem horizontal, fazendo com que os usuários não gastem tempo para percorrer grandes massas de informação de baixa densidade (Nielsen, 2012).

As análises de usabilidade permitem que se possa concluir que o Flat Design pode apresentar problemas de usabilidade devido à simplificação dos elementos da interface, ocasionando problemas de interação. O flat possui como uma de suas premissas facilitar a compreensão dos elementos e interação dos usuários, tornando sua experiência mais prática e fácil. No entanto, conforme mostrou a análise de usabilidade, existem problemas no entendimento dos elementos da interface, dificultando a interação dos usuários coma mesma. Parte dos usuários está acostumado com interfaces que possuem sombras, efeitos 3D, botões com box retangulares, entre outros. Esses elementos não existiam "por acaso": eles auxiliavam a compreensão do que era um elemento de interface. Desta forma, ao se depararem com uma interface sem profundidade, com cores sólidas e baixa densidade informacional existe um grande estranhamento. Assim, embora o Flat Design possua uma estética visual atrativa, por fugir do "convencional" e quebrar padrões de web design, existe uma necessidade de melhorar a sua usabilidade para que o usuário consigo compreender suas interações.

\section{CONCLUSÃO}

A estética exerce grande influência no design, sendo uma forma de tornar uma interface mais agradável e atrativa. Ao observar o design das primeiras interfaces gráficas do usuário (GUIs) é possível notar uma evolução no refinamento estético, proporcionando melhorias não só visualmente como também na compreensão dos elementos da interface. O Flat Design é uma tendência visual contemporânea caracterizada pela simplificação dos elementos de interface, com foco na forma, funcionalidade e tecnologia. 
A estética flat surge para confrontar a tendência estética utilizada desde as primeiras interfaces gráficas: o Skeuomorphism, caracterizado por imitar a vida analógica no ambiente digital; e para isso utilizar uma profusão de elementos visuais, tais como: sombra, texturas, chanfros, elementos 3D, gradientes, entre outros. Além disso, o surgimento de novos dispositivos com diferentes tamanhos de tela fez com que se tornasse necessária uma prática de um web design que fosse adaptável e redimensionável para várias resoluções: o web design responsivo. O Flat Design torna a prática do web design responsivo mais eficaz, pois devido a utilização de cores sólidas e poucas imagens, torna-se mais fácil realizar as adaptações para os diferentes dispositivos, sem perder a qualidade do projeto.

O Flat Design possui uma estética característica, possuindo um grande apelo para a utilização de formas puras, cores sólidas e vibrantes, utilização de grid e de módulos, entre outros. A união destes elementos resulta em um layout alegre, vibrante e atrativo. No entanto, a tendência apresenta desvantagens relacionadas sobretudo a usabilidade e interação. Os testes e análises de Nielsen (2012) e Budiu (2013) evidenciam a dificuldade de alguns usuários em identificar elementos básicos de uma interface, como botões e links. Isso deve-se principalmente a utilização de botões planos, sem sombras ou gradientes que transmitiam a sensação de profundidade. Outro ponto levantado é com a ausência de um box retangular para reforçar que aquele elemento é clicável; muitas interfaces flat utilizam apenas um rótulo com uma tipografia para servir como um botão. A densidade informacional também é apontada por Nielsen (2012) como um desvantagem da tendência, acabando por dificultar a interação do usuário, fazendo com que ele tenha uma rolagem gigante para visualizar uma pequena quantidade de informação. Desta forma, é possível constatar que a estética flat pode ocasionar problemas de usabilidade e interação ao usuário, gerando grande frustração e descontentamento com a nova tendência.

Com base no todo exposto, é importante salientar que Flat Design não é a solução para todo e qualquer projeto de design. Cada projeto possui suas características próprias e especificidades e cabe ao design analisar junto ao cliente qual serão os objetivos traçados. A partir disso, o designer possui a competência e a autonomia de definir a melhor solução estética para o projeto, buscando minimizar danos com relação a usabilidade e interação.

\section{REFERÊNCIAS}

BUDIU, Raluca. los 7 user-experience appraisal. Nielsen Norman Grupo, 19 outubro 2013. Disponível na internet http em: <http://www.nngroup.com/articles/ios-7/>. Acesso em 13 jan 2016.

CALDAS, Dario. Observatório de sinais: teoria e prática da pesquisa de tendências. Rio de Janeiro: Editora Senac, 2004.

DOLLAGHAN, Kelsey Campbel. O que é Flat Design? Gizmodo, 24 maio 2013.

Disponível na internet por http em: <http://gizmodo.uol.com.br/o-que-e-flat-design/> Acesso em 10 ago 2016.

LAKATOS, E. M.; MARCONI, M. Fundamentos de Metodologia Científica. São Paulo: Atlas, 2010. 
LUPTON, E.; PHILLIPS, J. Novos fundamentos do design. São Paulo: Cosac \& Naify, 2008.

MARCOTTE, Ethan. Responsive Web Design. Nova lorque: A book apart, 2011

MEGGS, Philip B.; PURVIS, Alston W. História do Design Gráfico. São Paulo: Cosac Naify, 2009.

NIELSEN, Jakob. Windows 8 - Disappointing usability for both novice and power users. Nielsen Norman Grupo, 19 novembro 2012. Disponível na internet por http em: <http://www.nngroup.com/articles/windows-8-disappointing-usability/>. Acesso em 13 jan 2016

NORMAN, Donald. O design do dia-a-dia. Rocco 2006. 